\title{
ESPAÇO, TERRITÓRIO E SAÚDE: CONTRIBUIÇÕES DE MILTON SANTOS PARA O TEMA DA GEOGRAFIA DA SAÚDE NO BRASIL
}

\section{Space, territory and health: contributions of Milton Santos for the theme of the geography of health in Brazil}

\author{
Rivaldo Mauro de FARIA ${ }^{1}$
}

Arlêude BORTOLOZZI²

\begin{abstract}
RESUMO
O presente artigo tem como objetivo discutir a importância dos conceitos de espaço e território em Milton Santos nos estudos sobre Geografia da Saúde no Brasil. Estes conceitos foram incorporados pela ciência epidemiológica a fim de buscar instrumentos teórico-metodológicos que Ihe permitissem entender o processo saúde-doença como manifestação social. É vasta a literatura que trata das questões espaciais/territoriais em saúde e Milton Santos pode ser considerado um dos grandes influenciadores desse movimento. $O$ texto introduz essa reflexão e, ao mesmo tempo, destaca a importância da categoria território, tratada na obra desse mesmo autor, para a prática da investigação e gestão em saúde pública.
\end{abstract}

Palavras-chaves: Geografia da Saúde; espaço; território; Milton Santos; processo saúde-doença.

\begin{abstract}
The present article intends mostly to discuss the importance of Milton Santos's concepts of space and territory, related in Health Geography in Brazil. These concepts have been incorporated by epidemiologic science in order to search theoretical and methodological instruments, which could help to understand health-illness process as a social manifestation. The literature field that discusses spatial and territory in health, and Milton Santos can be considered one of the greatest leaders of that movement. This paper introduces this reflection and, at the same time, detaches the importance of territory concept for inquiry practicality and public health management.
\end{abstract}

Keywords: Geography of Health; Space; Territory; Milton Santos; Illness-health process.

1 Mestre e Doutorando em Geografia pelo Instituto de Geociências da Unicamp.

2 Dra em Educação. Pesquisadora do Nepam/Unicamp (Núcleo de Estudos e Pesquisas Ambientais). Docente da Pós-Graduação em Geografia do Instituto de Geociências da Unicamp. 


\section{OBSERVAÇÕES INTRODUTÓRIAS}

As maiores preocupações da ciência no limiar do século XXI estão relacionadas com as condições da existência humana. O discurso dos problemas ambientais de proporções internacionais ganhou consistência e recentemente alarmou a sociedade mundial sobre a possibilidade de um aquecimento global irreversível. A globalização da natureza é acompanhada pela globalização dos problemas ambientais (GONÇALVES, 2006). Ainda que as consequências desse processo sejam distribuídas desigualmente nas diversas regiões do mundo, essas questões começam a preocupar os países desenvolvidos, já que a natureza não reconhece as fronteiras territoriais.

Ao lado da globalização da natureza e, em parte, a globalização dos problemas ambientais, que começam a tomar lugar na pauta das reuniões políticas internacionais, há também a globalização da saúde. $\mathrm{Na}$ configuração de um mundo em rede (CASTELLS, 2002), uma das características principais do mundo globalizado, tornou possível os fluxos de vírus e bactérias, que podem se alastrar rapidamente nas diversas regiões do globo e produzir grandes epidemias. Nesse contexto, a Geografia se apresenta, de um lado, como a ciência do estudo das relações entre a sociedade e a natureza, e, portanto, se vê fortalecida e desempenha um papel fundamental nas análises ambientais nas diversas escalas, e de outro, como a ciência do estudo do espaço e, nesse caso, irá ao encontro das necessidades enfrentadas pela Epidemiologia.

A aproximação entre essas duas ciências é histórica, em especial na vertente denominada Geografia Médica, considerada, por alguns, como em Rodenwalt (apud PESSOA, 1978), um ramo da Epidemiologia, e em outros, como em Sorre (1951), um ramo da Geografia. No decorrer dessa história, a Epidemiologia foi incorporando gradativamente o conceito de espaço trabalhado na Geografia e fez dessa categoria uma importante ferramenta para a análise da manifestação coletiva da enfermidade (CZERESNIA; RIBEIRO, 2000). Uma leitura dos manuais de Epidemiologia como o que foi desenvolvido por Medronho et al (2005) pode mostrar capítulos inteiros dedicados ao ensino das técnicas de análises espaciais, as quais são trabalhadas pela Geografia. Entre essas técnicas, destaca-se a utilização das ferramentas do SIG (Sistema de Informação Geográfica), pela sua capacidade de agrupar uma grande quantidade de dados e sua respectiva localização.

As mudanças impostas pela "nova" sociedade que se desenvolve a partir da década de 1970 vêm fortalecer a categoria espaço e território nas pesquisas em saúde pública. Por um lado, as mudanças no perfil de morbimortalidade da população, caracterizada pela redução das doenças infecciosas e o aumento das doenças crônico-degenerativas, e, por outro, a emergência de novas enfermidades, como a Aids, são responsáveis pela crise que se instaura na ciência epidemiológica no sentido de buscar formas mais eficientes de entender a doença como manifestação coletiva.

É nesse contexto que os trabalhados desenvolvidos por Harvey $(1980 ; 2006)$, Lefebvre $(2001 ; 2002)$, Soja (1993), Santos (1978; 1988; 1997; 2004), entre outros, serão norteadores de uma nova concepção de espaço, assim como o revigoramento dessa categoria na pesquisa social crítica. Os debates produzidos pela chamada "Geografia Crítica" serão inseridos na vertente denominada "Epidemiologia Social Crítica", a fim de superar os aportes herdados da clínica e incorporar conceitos das ciências sociais.

O presente artigo pretende introduzir essa reflexão a partir do estudo da influência da obra de Milton Santos no debate sobre saúde no Brasil. Esse que se dedicou incansavelmente aos temas da Geografia, em especial aos conceitos de espaço e território, (SANTOS, 2003a), fez-se notar em diferentes ramos do saber, ainda que, muitas vezes, não estivesse diretamente presente. O texto procura destacar a influência desse autor nos estudos sobre espaço e saúde no Brasil (primeira parte) e, ao mesmo tempo, discute a importância da categoria território, proposta na obra desse mesmo autor, para a prática da investigação e gestão em saúde pública (segunda e terceira partes). O tema deve contribuir para o importante debate que vem sendo produzido por um número cada vez maior de pesquisadores preocupados com a Geografia da Saúde no país. 
FARIA, R. M.; BORTOLOZZI, A. Espaço, território e saúde: contribuições de...

\section{A GEOGRAFIA DA SAÚDE EM MILTON SANTOS ${ }^{3}$}

A reflexão sobre o pensamento de Milton Santos e a saúde pública brasileira se faz, obviamente, pela influência que a vasta produção teórica desse autor legou para a ciência em geral e para a saúde pública em particular. Não que Milton Santos tivesse dedicado parte de sua vida em estudos sobre Geografia da Saúde, mas certamente a preocupação desse autor com o objeto da ciência geográfica acabou por proporcionar uma revisão epistemológica do conceito de espaço e território e, dessa forma, ser capaz de influenciar as demais ciências, como a Economia, a Sociologia e a Epidemiologia.

No contexto da experiência brasileira, observamse poucos trabalhos de geógrafos dedicados ao tema da saúde. De acordo com Guimarães (2001), há uma grande quantidade de epidemiologistas trabalhando com as ferramentas da geografia, mas a mão contrária não se faz com a mesma intensidade. Cita-se como um dos mais importantes, a figura inesquecível de Josué de Castro ${ }^{4}$, que através da sua "Geografia da Fome" (CASTRO, 1957) conseguiu integrar conhecimentos geográficos e de saúde. Aliás, vale lembrar aqui que o tema da alimentação foi também objeto de uma publicação de Milton Santos em 1967, denominada "Croissance Démographique et Consommation Alimentaire dans les pays sousdéveloppés" (apud, SANTOS, 1996). Não é difícil supor, sem correr o risco de exageros, que Milton Santos, provavelmente influenciado por Josué de Castro, também se preocupava com as mazelas da saúde pública, especialmente com aquelas relacionadas ao problema da fome.

A influência de Milton Santos nas pesquisas em saúde pública brasileira pode ser observada por dois aspectos principais relacionados com as novas questões sociais e científicas que emergiram a partir da década de 1970. O primeiro pode ser caracterizado pela fragilidade, que se revela numa certa incapacidade da ciência epidemiológica no entendimento do processo saúde-doença no contexto de profundas mudanças sociais do período: mudança do perfil epidemiológico; processo de urbanização e a intensificação das relações sociais; novas possibilidades epidêmicas causadas pelo processo de globalização, surgimento de novas doenças e o reaparecimento de doenças potencialmente controladas, impactos ambientais e sua relação com a saúde, etc. O quadro se vê agravado pela dificuldade para a Epidemiologia superar uma abordagem descritiva e reducionista, influenciada por certo positivismo herdado do século XIX, que a torna bastante debilitada para fazer relações importantes na explicação do fenômeno biológico. Citam-se, por exemplo, as questões paradigmáticas e ainda não resolvidas da relação entre o individual e o coletivo, o biológico e o social ou entre a sociedade e a natureza. Essas questões passaram a ser amplamente debatidas, a partir de 1970, pelo movimento de renovação crítica dentro da Epidemiologia, através de trabalhos como o de Laurell (1983), Breilh (1991), Melo-Filho (1996), Almeida Filho (1989), entre outros.

O segundo aspecto que certamente coloca em evidência a obra de Milton Santos nas pesquisas em saúde pública é a renovação do pensamento geográfico nesse mesmo período. Essa renovação, que se faz como tentativa de superar uma visão de espaço meramente físico, será incorporada pela Epidemiologia. A concepção de espaço tratado na obra de Milton Santos será importante na medida em que vai possibilitar à Epidemiologia pensar essa categoria enquanto relação social e assim permitir pensar a doença enquanto processo de mudança da estrutura espacial, não meramente descrevendo-a (SILVA, 1985a). Outra contribuição importante, de acordo com Silva (1985a), é que, através da categoria espaço geográfico, a Epidemiologia pôde superar uma visão não histórica do processo biológico e ao mesmo tempo entender os fatores econômicos, sociais, políticos e culturais responsáveis pela produção das doenças endêmicas e epidêmicas. "O conceito de espaço geográfico incorpora os determinantes naturais e sociais numa visão de totalidade, que muitas vezes falta à análise epidemiológica" (SILVA, 1997, p. 588). Quase que parafraseando essa afirmação, Costa e Teixeira (1999, p. 275) afirmam que:

3 Ao destacar a influência de Milton Santos na investigação em saúde não se quer negligenciar aqueles autores brasileiros que trataram o tema diretamente. Refere-se aqui tanto os autores tradicionais como Josué de Castro, Samuel Pessoa e Carlos da Silva Lacaz, quanto os autores mais atuais como Luis Jacinto da Silva (Unicamp), Paulo C. Sabroza (Fiocruz), Maurício L. Barreto (UFBA), Christovam Barcellos (Fiocruz), Francisco Mendonça (UFPR), Raul Borges Guimarães (UNESP), Samuel do Carmo Lima (UFU), Marcos César Ferreira (Unicamp), entre tantos outros.

4 De acordo com Gonçalves (2006), Josué de Castro conseguiu antecipar um debate que mais tarde seria chamado de sócioambiental. Reconhece a fome como uma questão ambiental e, ao mesmo tempo consegue superar uma abordagem ecológica fragmentada das relações entre a sociedade e a natureza. Josué de Castro dedicou sua vida para a questão da fome (diga-se de passagem, talvez seja um dos maiores problemas em saúde pública mundial), foi um dos responsáveis pela criação da FAO, organização que também presidiu. 
FARIA, R. M.; BORTOLOZZI, A. Espaço, território e saúde: contribuições de...

O espaço geográfico apresenta-se para a epidemiologia como uma perspectiva singular para melhor apreender os processos interativos que permeiam a ocorrência da saúde e da doença na coletividade

Essa preocupação em entender o fenômeno biológico como processo social, espacial e temporalmente determinado orientou diversos pesquisadores como Silva (1985a; 1985b; 1997), Barreto e Carmo (1994), Barreto (2000), Sabroza e Leal (1992), Sabroza e Kawa (2002), Barcellos e Bastos (1995; 1996), Barcellos e Pereira (2006), Barcellos (2000), Monken e Barcellos (2005), Najar e Marques (1998), Ferreira (1991), Costa e Teixeira (1999), Rojas (1998), Rojas e Barcellos (2003), Czeresnia e Ribeiro (2000), Guimarães (2001; 2005) e muitos outros que buscaram na geografia, especialmente em Milton Santos, uma forma de entender o comportamento espacial do processo saúde-doença. No Brasil, esses trabalhos serão realizados principalmente na Escola Nacional de Saúde Pública da Fundação Oswaldo Cruz, Instituto de Saúde Coletiva da Universidade Estadual da Bahia e na Universidade Estadual de Campinas - esta última tendo como referência as pesquisas desenvolvidas por Luiz Jacinto da Silva (ROJAS; BARCELLOS, 2003).

De acordo com Czeresnia e Ribeiro (2000, p. 602), "os conceitos de espaço geográfico propostos por Milton Santos constituem uma das referências mais importantes para as análises da relação entre espaço e doença, especialmente as produzidas no Brasil". Essa importância será reconhecida, sobretudo, no estudo das doenças endêmicas, porque permite entender a sua produção e distribuição como o resultado da organização social do espaço (CZERESNIA; RIBEIRO, 2000). A influência de Milton Santos na epidemiologia brasileira é reconhecida também por Barreto (2000, p. 613), segundo o qual:

[...] na perspectiva da epidemiologia social, é a divulgação dos trabalhos de Milton Santos, principalmente aqueles produzidos a partir da segunda metade da década de 70 , que tem um impacto significante, pois trazia no conceito de espaço a possibilidade de articular os complexos elementos da dinâmica das sociedades, bem como da sua historicidade.

A concepção de espaço defendida por Santos (1997; 2004) envolve ao mesmo tempo a forma (os objetos contidos no espaço) e a função (as ações que se fazem em relação aos objetos). Sua principal contribuição se faz no sentido de entender o espaço como processo e produto das relações sociais, que se realiza enquanto uma instância social (SANTOS, 1997). Resumidamente o autor o define como

[...] um conjunto indissociável, solidário e também contraditório, de sistemas de objetos e sistemas de ações, não considerados isoladamente, mas como quadro único na qual a historia se dá (SANTOS, 2004, p. 63).

Ao abordar o espaço nessa perspectiva, Santos permite pensá-lo para além das geometrias, pois, na medida em que coloca o papel central das relações sociais na sua produção torna-se ele mesmo uma categoria relacional, que se realiza como processo, movimento ou fluxo. Isso ocorre porque, as formas "[...] estão sempre mudando de significação, na medida em que o movimento social lhes atribui, a cada momento, frações do todo social [...]" (SANTOS, 1997, p. 2). Ou seja, para cada período de tempo as formas terão novos conteúdos e ao mesmo tempo novas funções. Haverá, então, uma dialética forma-conteúdo que se manifesta também como uma dialética socioespacial. Nas palavras do autor:

Pode-se dizer que a forma, em sua qualidade de formaconteúdo, está sendo permanentemente alterada e que o conteúdo ganha uma nova dimensão ao encaixar-se na forma. A ação que é inerente à função, é condizente com a forma que a contém: assim, os processos apenas ganham inteira significação quando corporificados. (SANTOS, 1997, p. 2).

Ao pensar a categoria espaço como processo social, Santos destacou a importância da técnica ${ }^{5}$ para o seu entendimento. Obviamente, uma vez que o processo social se realiza pela ação, não é possível entendê-lo negligenciando as técnicas - "conjunto de meios instrumentais e sociais, com os quais o homem realiza sua vida, produz e, ao mesmo tempo, cria seu espaço" (SANTOS, 2004, p. 29). Não é por acaso que Santos inicia uma das suas mais importantes obras - A Natureza do Espaço - fazendo a discussão da importância das técnicas na análise espacial. A análise das densidades dos sistemas técnicos, que são diferentes 
FARIA, R. M.; BORTOLOZZI, A. Espaço, território e saúde: contribuições de...

para cada lugar, permite entender as mudanças temporais do espaço, os fluxos e as diferentes velocidades.

A categoria espaço em Milton Santos permitiu à Epidemiologia mudar o foco usual de análise centrada na doença para a análise das condições de ocorrência das mesmas (SILVA, 1997). Ao fazer isso passou a entender os mecanismos relacionais que explicam a distribuição e o desenvolvimento da enfermidade. O estudo da distribuição da esquistossomose no município de São Paulo, realizado por Luís Jacinto da Silva (SILVA, 1985b), é um exemplo de trabalho formulado nessa linha. $O$ autor conseguiu mostrar que a explicação principal para a disseminação dessa doença no município de São Paulo não é o fluxo migratório NordesteSudeste, como até então se imaginava. Ao analisar as condições espaciais da produção da esquistossomose pôde-se notar que foi a evolução urbana e os moldes em que se deu essa evolução o fator mais relevante na produção dessa doença neste município. Isso porque, explica o autor, não fosse a expansão urbana para áreas de vale, a doença não teria encontrado as condições ecológicas propícias para sua transmissão.

Luis Jacinto da Silva é considerado um dos pioneiros da inserção do conceito de espaço geográfico nos estudos epidemiológicos. Fez isso não só no estudo da esquistossomose, como também na investigação da disseminação e distribuição espacial da doença de chagas no Estado de São Paulo (1985a). Outras experiências, como as que foram desenvolvidas por Barreto (1994), também podem ser mencionadas como modelos de trabalhos desenvolvidos nessa mesma linha. Ao investigar a distribuição espacial da esquistossomose do Estado da Bahia, o autor conseguiu integrar os conceitos de espaço geográfico e, assim, pôde entender o comportamento epidemiológico dessa enfermidade.

Tarefa quase impossível em um artigo destacar a grande quantidade de trabalhos formulados na linha de estudo proposta por Milton Santos. Essa influência compreende não só os geógrafos dedicados ao tema da saúde, como também, os médicos, epidemiologistas e sanitaristas. Aliás, grande parte dos autores citados até aqui não são geógrafos. Merece destacar a importância que os eventos ligados à Geografia da saúde no Brasil têm representado para esse debate, em especial, o Seminário Nacional de Geografia da Saúde cuja terceira edição foi realizada em Curitiba no ano de 2007.

A influência de Milton Santos na área da saúde pode ser evidenciada na participação desse geógrafo em um dos eventos do Centenário da Fundação Oswaldo Cruz em 2000, uma das poucas participações do autor em eventos sobre saúde pública. Com o tema "Saúde e Ambiente no Processo de Desenvolvimento",
Santos fez uma crítica ao determinismo que ainda acompanha as pesquisas sobre ambiente e saúde, ao mesmo tempo em que destacou o desvirtuamento da teoria e da prática científica.

Um saber e uma prática bem descolados de preocupações humanísticas são a principal marca do domínio da técnica sobre a ciência que estamos assistindo: é a técnica que está ditando as escolhas possíveis dos remédios (SANTOS, 2003b, p. 312).

Ao destacar a supervalorização da técnica, Santos mostra o papel avassalador que o mercado desempenha no setor saúde nos dias atuais. Essa influência mercadológica acabou determinando uma produção pragmática cujas formulações começam no resultado e não nas causas e, por isso, não atinge a maior parte da população (espacialmente segmentada) que não tem acesso à saúde. A conferência proferida por Santos trata de expor a importância do pensamento livre, da produção intelectual que se preocupe com as questões humanitárias, ao mesmo tempo em que faz uma crítica à privatização do saber e da universidade, acompanhada também pela privatização da cidade. Vai dizer o autor que a ciência se viu suplantada pela técnica num momento em que "a globalização veio sem que viesse junto um mundo só" (SANTOS, 2003b, p. 313). Por isso mesmo, a questão se afirma para além da técnica, trata-se de uma questão de economia política e de distribuição do poder e da riqueza (SANTOS, 2003b).

Essa talvez seja a grande contribuição de Milton Santos à saúde pública brasileira e que acabou motivando uma grande quantidade de pesquisadores a utilizarem os referenciais teóricos desse autor nas pesquisas sobre disseminação de doenças nas coletividades. Ao entender o espaço no contexto do desenvolvimento técnico-científico-informacional o setor saúde passa a entender a doença não apenas como o resultado da presença de vírus e bactérias (análise unicausal), mas, como resultado de uma dinâmica social complexa. Embora tenha referido ser "[...] apenas um observador das questões médicas [...]" (SANTOS, 2003b, p. 312) a sua contribuição à saúde foi e tem afirmado ser extremamente profícua e cada vez mais necessária.

Ao destacar o papel da economia política e das relações sociais de poder na produção do espaço, Santos (1998b) aponta a importância da categoria território nas análises geográficas. Entendido como uma categoria de análise social, o território se apresenta como o recorte ou fração do espaço qualificado por seu sujeito. "A categoria analítica é o território usado pelos homens, tal qual ele é, isto é, o espaço vivido pelo homem [...]" (SANTOS, 2003b, p. 311). Tendo em vista a importância 
FARIA, R. M.; BORTOLOZZI, A. Espaço, território e saúde: contribuições de...

que essa categoria vem adquirindo nas pesquisas e planejamento em Saúde, algumas considerações serão feitas sobre o tema.

\section{O CONCEITO DE TERRITÓRIO E SUA IMPLICAÇÃO PARA A SAÚDE PÚBLICA}

Em primeiro lugar, impõe-se uma importante questão: como conciliar, na prática, uma pesquisa que trabalhe a categoria espaço e o processo saúde-doença conjuntamente? Para Luckesi (1991, p. 49) "[...] o conhecimento só nasce da prática com o mundo, enfrentando os seus desafios e resistências [...]". Portanto, ao pretender uma pesquisa, a primeira coisa a se perguntar é a sua viabilidade prática, ou seja, o seu desdobramento social. É indiscutível que as ciências médicas, sobretudo a saúde pública, têm feito contribuições fantásticas na melhoria das condições de saúde da sociedade humana. No entanto, é bem verdade também que as grandes descobertas realizadas pelas ciências médicas não atingem a sociedade como um todo ou, se atingem, o fazem de forma parcial e lenta. A questão de ética e da capitalização/mercadorização do setor saúde foi tratada por diferentes autores como em Negri e Di Giovanni (2001) que se preocupam com a questão do acesso e do direito a saúde

A geografia do acesso ou a geografia da exclusão social pode revelar claramente a distância entre a teoria e a prática, processo que aponta também para o distanciamento entre a universidade e a sociedade (SANTOS, 2003b). É nesse sentido que a categoria território se mostra pertinente, tanto no que se refere ao alcance social dos bens produzidos pela sociedade moderna, quanto para a investigação das realidades sociais mais deploráveis. Se de um lado o território cenário das relações sociais -, pode ser essencial para investigar a apropriação/dominação do espaço e sua relação com a saúde, de outro, torna-se importante para o planejamento de ações que permitam diminuir os impactos dessa apropriação na vida das pessoas. Como exemplo importante pode-se citar o planejamento territorial urbano que pode tanto evitar a produção de doenças, controlando a ocupação de áreas inadequadas e criando uma estrutura ambientalmente saudável, quanto tornar mais eficaz a ação da saúde pública, instalando equipamentos e serviços que sejam condizentes com as realidades territoriais a que se destinam.

No entanto, duas questões se colocam fundamentais para uma prática territorial em saúde. Primeiramente, deve-se ter claro o que se entende pela categoria território, uma vez que é essa definição que vai fornecer os parâmetros para a identificação de áreas para a implementação de ações práticas em saúde. Em segundo lugar, deve-se entender quando e quais as práticas de saúde podem ser compreendidas numa análise territorial.

Com relação à primeira questão, uma breve investigação etimológica da palavra território pode revelar os significados dessa expressão como "terra pertencente a" - terri (terra) e torium (pertencente a) -, de origem latina; ou como "terreo-territor" (aterrorizar - aquele que aterroriza) de origem grega (HAESBAERT, 2004). Tratase de um conceito ambíguo, com oscilações de significados e compreendido de forma diferente por áreas como a Biologia (etologia), Ciências Políticas (Estado) e Antropologia (territorialidade), etc. (BARCELLOS; PEREIRA, 2006). De modo geral, e isso pode ser notado nos diversos campos do saber, o conceito de território esteve quase sempre relacionado com as relações de poder que se estabelecem entre os grupos sociais e destes com a natureza (RAFESTIN, 1993). Ou seja, a sua definição se faz pela apropriação/dominação de uma área por um determinado grupo social.

A definição de uma área territorial para implementação de ações práticas em saúde irá depender diretamente da concepção teórica e política do pesquisador/ planejador. Aliás, são essas diferentes concepções que fizeram alimentar diferentes abordagens territoriais (SAQUET, 2007) e cada uma dessas abordagens permitem definir territórios, não só em escalas geométricas variadas, como também com olhares os mais variados. Assim sendo, a definição do território para aqueles que defendem uma abordagem política será comumente confundida com os limites do Estado-Nação. Os que dão ênfase aos aspectos econômicos irão destacar a produção, o consumo e a atuação das grandes empresas. Àqueles que se preocupam com os aspectos culturais darão maior relevância às qualidades simbólicas e ideárias e, por fim, os que enfatizam os aspectos físicos do território terão preocupações relacionadas com a utilização dos recursos e a questão ambiental (HAESBAERT, 2004). Ou seja, a polissemia do termo e o fato de se tratar de uma categoria interdisciplinar (MONKEN; BARCELLOS, 2005), permite entender o território por diferentes nuances, podendo até mesmo ser definido como a área de atuação do crime organizado ou o território virtual presente nas relações feitas pela internet (SOUZA, 1995).

Um trabalho recente desenvolvido por Saquet (2007) permite visualizar as diferentes abordagens do conceito de território trabalhadas por autores italianos, franceses, ingleses e americanos, além da síntese dos 
principais autores que discutem o tema no Brasil. De acordo com esse autor, os estudos territoriais ganharam destaque na Geografia a partir da década de $1970 \mathrm{com}$ o movimento de renovação crítica dessa ciência e a busca de novos modelos de análise espacial. O estudo desses trabalhos permitiu a Saquet (2007) identificar quatro tendências ou perspectivas de abordagem do território:

a) uma eminentemente econômica. Sob o materialismo histórico dialético, na qual se entende o território a partir das relações de produção e das forças produtivas; b) outra, pautada na dimensão geopolítica do território; c) a terceira, dando ênfase às dinâmicas política e cultural, simbólica-idenditária, tratando de representações sociais centrada na fenomenologia e, d) a última, que ganha força a partir dos anos de 1990, voltada às discussões sobre a sustentabilidade ambiental e ao desenvolvimento local, tentando articular, ao mesmo tempo, conhecimentos e experiências de maneira interdisciplinar (SAQUET, 2007, p. 15).

No Brasil, destaca-se a influência de três autores ou correntes de análise territorial. A primeira foi produzida a partir da vasta obra de Milton Santos, seguida, alguns anos mais tarde, pelas contribuições dadas pelos pesquisadores Rogério Haesbaert e Marcos Saquet.

\begin{abstract}
Milton Santos elabora uma argumentação de caráter eminentemente epistemológica, pautada em processos sociais e reconhecendo a natureza como um elemento do território; R. Haesbaert faz uma discussão teórica e ontológica centrada na reterritorialização a partir de fatores políticos e culturais, incorporando mais recentemente uma preocupação mais sistemática com a natureza e, M. Saquet, efetiva uma discussão teórico-metodológica, destacando a produção do território sob as forças econômicas, políticas e culturais [...] (SAQUET, 2007, p. 122).
\end{abstract}

Cada uma das abordagens acima pode ser transposta para uma investigação em saúde, assim como foi feito em obras de Monken e Barcellos (2005), Barcellos e Pereira (2006), Rigotto e Augusto (2007), entre outros. Uma vez que os objetivos da pesquisa foram previamente determinados deve-se fazer a escolha da abordagem territorial que melhor comunique esses mesmos objetivos.

A segunda questão que foi levantada inicialmente diz respeito à viabilidade prática da categoria território nas investigações e no planejamento em saúde. Isso porque, não é possível pensar que o território seja a solução para todos os males da saúde pública. Fosse assim, a atividade imunológica e o laboratório seriam desnecessários. No entanto, o território pode contribuir tanto para a ação desses meios (vacinação, análise laboratorial, investigação etiológica, etc.) na medida em que revela as áreas carentes, quanto é importante para diminuir a utilização dos mesmos. É nesse sentido que essa categoria torna-se essencial para adequar, da melhor forma possível, as ações em saúde primária. Ou seja, o objetivo é otimizar as ações de caráter preventivo e ao mesmo tempo evitar a sobrecarga das ações de caráter corretivo, que quase sempre são resolvidas nos hospitais. Nesse sentido o território torna-se uma ferramenta, não a única, e deve ser utilizada sempre que a investigação/ação envolver grupos sociais.

\section{TERRITÓRIO URBANO, CIDADANIA E SAÚDE PÚBLICA}

As novas abordagens do conceito de território que vêm sendo trabalhados nas últimas décadas, em especial na obra de Milton Santos, têm como característica principal o rompimento com a tradicional visão política dessa categoria. Até recentemente o território era definido como a área de atuação do Estado e, por isso, suas divisões compreendiam apenas as instâncias do poder público federal, estadual e municipal.

Ao entender o território enquanto apropriação social (política, econômica e cultural) um salto qualitativo foi dado, tanto no que se refere às escalas quanto às funções que cada recorte territorial admite. É nessa perspectiva que essa categoria ganha dinamicidade, alterando-se a partir do jogo conflituoso (de poder) próprio das relações sociais. O entendimento do território como algo móvel e transitório foi um dos motivos que levaram diferentes pesquisadores como Haesbaert (2004) a defender o aparecimento e desaparecimento dos territórios, assunto que não será tratado nesse texto.

Uma vez que o território é determinado pelas diferentes funções espaciais ou pelos diferentes usos espaciais, não é possível entendê-lo ignorando as relações políticas e econômicas que se estabelecem no modelo capitalista de produção (SANTOS, 1998b). Ao entender essas relações, que se desdobram em diferentes funções-usos espaciais, torna-se possível delimitar territorialmente um espaço para a implementação de ações práticas de saúde.

A abordagem do território nessa perspectiva permite estabelecer as relações entre os territórios em diferentes escalas. Assim, é possível transitar entre as escalas territoriais locais (acesso aos serviços, qualidade de vida, moradia, etc.) e sua relação com os mecanismos territoriais globais (políticas públicas, 
FARIA, R. M.; BORTOLOZZI, A. Espaço, território e saúde: contribuições de...

infraestrutura, economia, etc.) e, a partir daí, estabelecer a relação com os processos sociais como saúde, educação, renda, etc.

Essa relação dialética confere especificidade para cada nicho territorial, onde a relação espaço e processo saúde-doença podem ser entendidos. Tal observação parece se aproximar muito das proposições de Laurell (1983) sobre o perfil patológico da coletividade, que se manifesta diferente em cada grupo e pode ser interpretada em seu comportamento biológico-coletivo. O perfil patológico do grupo pode também ser entendido como uma manifestação do território, onde se circunscreve determinado comportamento.

No entanto, para a saúde pública essa reflexão atravessa certa obscuridade, uma vez que ainda são poucos os trabalhos que têm utilizado a categoria território como possibilidade de ações adequadas em saúde, sobretudo relacionadas ao planejamento. Nos postos de saúde, pode-se deparar, frequentemente, com mapas figurativos da sua área de atuação, que pouco ou quase nada representam para a efetiva tomada de decisões. A atividade cartográfica têm se apresentado como uma das mais importantes ferramentas para a análise em saúde pública, como foi destacado no trabaIho de Barcellos e Bastos (1996), porém, a investigação não pode se prender na utilização da ferramenta em si (FERREIRA, 2003).

A eficácia dos programas de saúde pública depende, visivelmente, de uma boa gestão territorial. Tal gestão, de acordo com Santos (1998b), deve garantir o acesso aos bens e serviços básicos para uma boa qualidade de vida. A gestão do território supõe ações integradas que contemplem a educação, saúde, moradia, saneamento básico, transporte, etc. Por isso, a exigência de um trabalho interdisciplinar que não se limita à visão dicotômica que muitas vezes se tem produzido em saúde no Brasil.

A busca por uma nova abordagem territorial em saúde, que contemple múltiplos olhares, apresenta-se ainda mais necessária em escala urbana, onde tudo se torna mais complexo. Obviamente as relações sociais mais intensas, os conflitos, os fluxos e os usos diferenciados produzem territórios e territorialidades as mais variadas. Nesses territórios urbanos diferenciados, o processo saúde-doença pode ser investigado como um evento diferenciado ou particular. O fenômeno biológico, como um fenômeno social, pode ser entendido em sua dependência territorial urbana.

A Epidemiologia Social fez progressos significativos no que se refere à interpretação coletiva da doença e acentuou a forte dependência social do fenômeno biológico. A inserção do pensamento geográfico, no sen- tido de contribuir para essa mesma investigação, pode revelar o perfil territorial do processo saúde-doença. De acordo com Breilh e Granda (1989, p. 40):

[...] do ponto de vista da Epidemiologia, o processo saúde-doença é a síntese do conjunto de determinações que operam numa sociedade concreta, produzindo, nos diferentes grupos sociais, o aparecimento de riscos ou potencialidades característicos, por sua vez manifestos na forma de perfis ou padrões de doença ou saúde.

A manifestação do perfil de saúde-doença numa população pode ser evidenciada territorialmente, como entidades espacialmente determinadas. Trata-se, nesse caso, de "analisar e apreender os aspectos espaciais e funcionais do território [...] e elaborar, a partir daí, os critérios para criar perímetros homogêneos no seu interior" (MEYER, 2006, p.39). Tais perímetros homogêneos se referem aos limites onde se verificam relações socioespaciais próprias e, por isso também, a manifestação de perfis biológicos próprios, que se adaptam e resultam das condições territoriais locais.

A necessidade de estabelecer os limites territoriais para a pesquisa invadiu quase todas as áreas preocupadas com o planejamento urbano. De fato, o urbanismo, a geografia, a arquitetura, a sociologia e, mais recentemente, a saúde pública têm inserido a categoria território como meio possível e eficaz para entender a dinâmica urbana. Tal necessidade está relacionada com a impossibilidade de entender o espaço urbano em sua totalidade, considerando as suas verticalidades e horizontalidades, ou seja, as suas relações internas e externas ao próprio território (SANTOS, 1998b).

Afinal, as relações urbanas são relações cada vez mais globalizadas (SANTOS, 2003a), sendo mesmo possível afirmar, com algumas reservas evidentemente, que a urbanização atingiu toda a sociedade, a chamada "sociedade urbana" (LEFEBVRE, 2001; 2002). Esse processo não é diferente no Brasil, onde o fenômeno urbano atingiu proporções nacionais (SANTOS, 1993). Esse espaço, fragmentado e fragmentador do ponto de vista territorial, é ao mesmo tempo integrado e integrador, no sentido de que as relações políticas e econômicas são cada vez mais externas ao próprio lugar e comandadas em alguns polos de decisões globais (SANTOS, 2003a). Sendo assim, como entender o território urbano senão estabelecendo as relações sociais nele existentes e os seus diferentes usos?

Outro ponto importante que deve ser considerado nas análises territoriais urbanas é o sentido da palavra territorialidade como sinônimo de pertencer àquilo que nos pertence (SANTOS, 2006). No território usado, 
empírico, as ações de cidadania são fundamentais para implantar um modelo adequado de investigação e atendimento em saúde. Aliás, pode-se fazer uma ótima aproximação entre o sentido dos termos territorialidade e cidadania. Por cidadania compreende-se os direitos sociais, o direito ao entorno, à moradia, à saúde, à educação, etc. (SANTOS, 1998a), em suma, o direito ao território urbano. Ora, essa reflexão faz emergir uma indagação importante: não seria a construção de espaços de não cidadãos (BORTOLOZZI; PEREZ, 1999; BORTOLOZZI, 2003) a explicação para os eventos de doença na cidade? Em outras palavras, não seria a produção de territórios de "não cidadãos" a razão para determinados comportamentos biológicos da sociedade?

A inserção da categoria território na investigação epidemiológica pode contribuir para esse debate, que está intimamente ligado com a questão da equidade e da universalidade no atendimento à saúde. Afinal, não são esses os pressupostos centrais contidos na organização do Sistema Único de Saúde (SUS) no Brasil? Sem dúvida, a prática do SUS pode ser facilmente entendida como uma prática territorial, pois deve compreender os direitos territoriais, entre os quais a saúde. Essa discussão foi feita nos trabalhos desenvolvidos por Mendes (1993), Unglert (1993) e Villarosa (1993), autores que defendem, sobretudo na implantação dos Distritos Sanitários, a necessidade de uma maior aproximação da saúde com os conceitos desenvolvidos nas ciências sociais, entre as quais a Geografia e a categoria território.

\section{CONSIDERAÇÕES FINAIS}

Os conceitos de espaço e território em Milton Santos inauguram um forte movimento em torno das questões geográficas da saúde brasileira sob moldes renovados. Não se trata de um movimento único,

\section{REFERÊNCIAS}

ALMEIDA FILHO, Naomar de. Epidemiologia Sem Números: uma introdução crítica à ciência epidemiológica. Rio de Janeiro: Campus, 1989.

BARCELLOS, Christovam. Elos entre a geografia e a epidemiologia. Cadernos de Saúde Pública, Rio de Janeiro, v. 16, n. 3, p. $607-609,2000$. tampouco pode ser comparado ao vigor da produção teórica de autores consagrados diretamente ao tema da Geografia Médica no país, como Josué de Castro, Samuel Bansley Pessoa, Carlos da Silva Lacaz, entre outros. Afinal, Milton Santos não esteve diretamente ligado à pesquisa em saúde, exceto em alguns poucos eventos em que esteve presente. No entanto, a sua preocupação com a natureza do espaço acabou por Ihe permitir comunicar-se, não apenas com as ciências da saúde, como também com a Economia, Ciências Políticas, entre outras.

De forma mais evidente a Epidemiologia, sobretudo depois da década de 1970, fez um movimento de aproximação com a Geografia, num momento de profundas mudanças na estrutura social e no pensamento. Processos relacionados à globalização e fragmentação, redes e fluxos, concentração populacional em áreas urbanas, entre outros, mudaram as formas de adoecer e morrer. Daí a necessidade de novos modelos teóricometodológicos que possibilitassem pensar o processo saúde-doença como manifestação coletiva e social.

A utilização dos conceitos de espaço e território em Milton Santos permitiu mudar o foco de atenção, que antes era centrado na doença, para os determinantes sociais das condições de saúde. A apropriação social do espaço produz territórios e territorialidades propícias à disseminação de determinadas enfermidades. Os usos e as funções que cada recorte espacial admite podem conformar perfis territoriais que revelam as condições de acesso aos serviços de saúde, exposição a fatores de risco, exclusão socioespacial, entre outros fatores determinantes das situações de saúde em grupos sociais.

Ao refletir sobre a categoria território na obra desse geógrafo, o texto apresentou uma ferramenta teórica, não a única, através da qual podem se orientar as práticas de investigação e gestão em saúde pública. Nesse sentido, uma contribuição foi dada aos muitos esforços que vem sendo realizados por geógrafos e epidemiologistas dedicados ao tema da Geografia da Saúde no país.
BARCELLOS, Christovam; BASTOS, Inácio. Geografia Social da Aids no Brasil. Revista de Saúde Pública, São Paulo, v. 29, n. 1, p. 52-62, 1995.

BARCELlOS, Christovam; BASTOS, Inácio. Geoprocessamento, ambiente e saúde: uma união possível? Cadernos de Saúde Pública, Rio de Janeiro, v. 12, n. 3, p. 389-397, 1996. 
FARIA, R. M.; BORTOLOZZI, A. Espaço, território e saúde: contribuições de...

BARCELLOS, Christovam; PEREIRA, Martha Priscila Bezerra. O território no Programa Saúde da Família. HYGEIA - Revista Brasileira de Geografia Médica e da Saúde, Uberlândia, v. 2 n. 2, p. 47-55, 2006. Disponível em: http:/www.ygeia.ig.ufu.br. Acesso em: 12/12/2007.

BARRETO, Maurício Lima; CARMO, Eduardo H. Esquistossomose Mansônica no Estado da Bahia, Brasil: Tendências Históricas e Medidas de Controle. Cadernos de Saúde Pública, Rio de Janeiro, v. 10, n. 4, p. 425-439, 1994.

BARRETO, Maurício Lima. O Espaço e a Epidemiologia: entre o conceitual e o pragmático. Cadernos de Saúde Pública, Rio de Janeiro, v. 16, n. 3, p. 613-614, 2000.

BORTOLOZZI, Arlêude; Perez Archimedes. Crise Ambiental da Modernidade e a Produção do Espaço-Lugar do Não Cidadão. Boletim Paulista de Geografia, São Paulo, n. 76, p. 7-21, 1999.

BORTOLOZZI, Arlêude. Educación Ambiental e Acción Social em el espacio brasileño: analisis de estudio de caso. In: IV CONGRESO IBEROAMERICANO DE E AMBIENTAL Y IV CONVENCIÓN DE MEDIO AMBIENTE Y DESAROLLO, 4., 2003, Habana-Cuba: CDRON-CITMA-Softcal-ISE-959-716445-0.

BREILH, Jaime. Epidemiologia: economia, política e saúde. São Paulo: Editora Unesp: Editora Hucitec, 1991.

BREILH Jaime; GRANDA, Edmundo. Investigação da saúde na Sociedade: guia pedagógico sobre um novo enfoque do método epidemiológico. 2. ed. São Paulo: Cortez, 1989.

CASTELLS, Manuel. A Sociedade em Rede. 6. ed. São Paulo: Paz e Terra, 2002.

CASTRO, Josué de. Geografia da Fome. São Paulo: Brasiliense, 1957.

COSTA, Maria da Conceição Nascimento; TEIXEIRA, Maria da Glória Lima Cruz. A concepção de "espaço" investigação epidemiológica. Cadernos de Saúde Pública, Rio de Janeiro, v.15, n. 2, p. 271-279, 1999.

CZERESNIA, Dina; RIBEIRO, Adriana Maria. O Conceito de Espaço em Epidemiologia: uma interpretação histórica e epistemológica. Cadernos de Saúde Pública, Rio de Janeiro, v. 16, n. 3, p. 595-613, 2000.

FERREIRA, Marcelo Urbano. Epidemiologia e Geografia: o complexo patogênico de Max. Sorre. Cadernos de Saúde Pública. Rio de Janeiro, v. 7, n. 3, p. 301-309, 1991.

FERREIRA, Marcos César. Procedimento Metodológico para Modelagem Cartográfica e Análise Regional de Epidemias de Dengue em Sistemas de Informação Geográfica. Tese (Livre docência) - Instituto de Geociências, Unicamp, Campinas, 2003.

GONÇALVES, Carlos Walter Porto. A Globalização da Natureza e a Natureza da Globalização. Rio de Janeiro: Civilização Brasileira, 2006.
GUIMARÃES, Raul Borges. Saúde Urbana: velho tema e novas questões. Terra Livre, São Paulo, n. 17, p. 155-170, 2001.

. Regiões de saúde e escalas geográficas. Cadernos de Saúde Pública, Rio de Janeiro, v. 21, n. 4, p. 1017-1025, 2005.

HARVEY, David. A Justiça Social e a Cidade. Tradução de: SILVA, A. C. da. São Paulo: Hucitec, 1980.

Condição Pós-Moderna: uma pesquisa sobre as origens da mudança cultural. Tradução de: UBIRAJARA, A.; GONÇALVES, M. S. 15. ed. São Paulo: Edições Loyola, 2006.

HAESBAERT, Rogério. O Mito da Desterritorialização: do fim dos territórios à multiterritorialidade. Rio de Janeiro: Bertrand Brasil, 2004.

LAURELL, Asa Cristina. A Saúde Como Processo Social. In: DUARTE, N. E. (Org). Medicina Social: aspectos históricos e teóricos. São Paulo: Editora Global, 1983. p. 133-158.

LEFEBVRE, Henry. O Direito à Cidade. Tradução de: FRIAS, R. E. São Paulo: Centauro, 2001.

A Revolução Urbana. Tradução de: MARTINS, S. Belo Horizonte: Editora da UFMG, 2002.

LUCKESI, Cipriano C. Fazer Universitário: uma proposta metodológica. 6. ed. São Paulo: Cortez, 1991.

MEDRONHO, Roberto de Andrade. et al. Epidemiologia. São Paulo: Atheneu, 2005.

MELO-FILHO, Djalma A. de. Antinomias e "saturas" epistemológicas entre biológico-social e individual-coletivo no âmbito da epidemiologia social. Revista Saúde Pública, São Paulo, v. 30, n. 4, p. 383-91, 1996.

MENDES, Eugênio Vilaça. Distritos Sanitários: processo social de mudanças nas práticas sanitárias para o Sistema Único de Saúde. São Paulo: Hucitec: Abrasco, 1993.

MONKEN, Maurício; BARCELLOS, Christovam. Vigilância em Saúde e Território Utilizado: possibilidades teóricas e metodológicas. Cadernos de Saúde Pública, Rio de Janeiro, v. 21, n. 3, p. 898-906, 2005.

MEYEER, Regina Maria Prosperi. O Urbanismo: entre a cidade e o território. Revista da Sociedade Brasileira para o Progresso da Ciência, São Paulo, v. 58, p. 38-41, 2006.

NAJAR, Alberto; MARQUES, Eduardo (Org.). Saúde e Espaço: estudos metodológicos e técnicas de análise. Rio de Janeiro: Fiocruz, 1998.

NEGRI, Barjas; DI GIOVANNI, Geraldo. Brasil: radiografia da saúde. Campinas: Unicamp, 2001.

PESSOA, Samuel Bansley. Ensaios Médico-Sociais. 2. ed. São Paulo: Editora Hucitec, 1978. 
FARIA, R. M.; BORTOLOZZI, A. Espaço, território e saúde: contribuições de...

RAFFESTIN, C. Por Uma Geografia do Poder. São Paulo: Ática, 1993.

RIGOTTO, Raquel Maria; AUGUSTO, Lia Giraldo da Silva. Saúde e Ambiente no Brasil: desenvolvimento, território e iniquidade social. Cadernos de Saúde Pública, Rio de Janeiro, v. 24, supl. 4, p. 475-501, 2007.

ROJAS, Iñigues Luisa. Geografía y Salud: temas y perspectivas em América Latina. Cadernos de Saúde Pública, Rio de Janeiro, v. 14, n. 4, p. 701-711, 1998.

ROJAS, Iñigues Luisa; BARCELLOS, Christovam. Geografia y Salud en América Latina: Evolución y Tendencias. Revista Cubana de Saúde Pública, Havana, v. 29, n. 4, p. 330-343, 2003. Disponível em: http://www.scielo.br. Acesso em: 15/03/2007.

SABROZA, Paulo Chagastelles; LEAL, Maria do Carmo. Saúde, Ambiente e Desenvolvimento: alguns conceitos fundamentais. In: SABROZA, Paulo Chagastelles et al (Org.). Saúde, Ambiente e Desenvolvimento: uma análise interdisciplinar. São Paulo/Rio de Janeiro: Hucitec/Abrasco, 1992. p. 45-93.

SABROZA, Paulo Chagastelles; KAWA, Hélia. Espacialização da leishmaniose tegumentar na cidade do Rio de Janeiro. Cadernos de Saúde Pública, Rio de Janeiro, v. 18, n. 3, p. 853-865, 2002.

SAQUET, Marcos Aurélio. Abordagens e Concepções de Território. São Paulo: Expressão Popular, 2007.

SANTOS, Milton. Por Uma Geografia Nova. São Paulo: Hucitec, 1978.

. Metamorfoses do Espaço Habitado: fundamentos teóricos e metodológicos da geografia. São Paulo: Hucitec, 1988.

1993.

A Urbanização Brasileira. São Paulo: Hucitec;

O Trabalho do Geógrafo no Terceiro Mundo. 4. ed. São Paulo: Hucitec, 1996.

. Espaço e Método. 4. ed. São Paulo: Nobel, 1997.

1998a.

O Espaço do Cidadão. 4. ed. São Paulo: Nobel,

O retorno do Território. In: SANTOS, Milton et al. (Org.). Território: Globalização e Fragmentação. 4. ed. São Paulo: Hucitec: Anpur, 1998b. p. 15-20.
Por Uma Outra Globalização: do pensamento único à consciência universal. Rio de Janeiro: Record; 2003a.

Saúde e ambiente no processo de desenvolvimento. Ciência e Saúde Coletiva, Rio de Janeiro, n. 1, v. 8, p. 309314, 2003b.

. A Natureza do Espaço: técnica, razão e emoção. 4. ed. São Paulo: Editora da Universidade de São Paulo, 2004.

O Brasil: território e sociedade no início do século

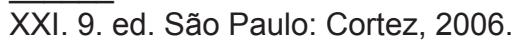

SILVA, Luis Jacinto. Organização do Espaço e Doença. In: CARVALHEIRO, J. R (Org.). Textos de Apoio: Epidemiologia I. 2. ed. Rio de Janeiro, v. 1, p. 159-185, 1985a.

Crescimento urbano e doença: a esquistossomose no Município de São Paulo (Brasil). Revista de Saúde Pública, São Paulo, v. 19, n. 1, p. 1-7, 1985b.

O Conceito de Espaço na Epidemiologia das Doenças Infecciosas. Cadernos de Saúde Pública, Rio de Janeiro, v. 13, n. 4, p. 585-593, 1997.

SOJA, Edward W. Geografias Pós-Modernas: a reafirmação do espaço na teoria social crítica. Rio de Janeiro: Jorge Zahar Editor, 1993.

SORRE, Max. Lês Fondements de la Géographie Humaine. Primeiro Tomo: Lês Fondements Biologiques (Essai d'une écologie de l'homme). 3. ed. Paris: Armand Colin, 1951.

SOUZA, Marcelo José Lopes. O território: sobre espaço e poder, autonomia e desenvolvimento. In: CASTRO, Iná Elias et al. Geografia: conceitos e temas. Rio de Janeiro: Bertrand Brasil, 1995. p. 77-116.

UNGLERT, Carmem Vieira de Souza. Territorialização em Sistemas de Saúde. In: MENDES, Eugênio Vilaça (Org.). Distritos Sanitários: processo social de mudança nas práticas sanitárias para o Sistema Único de Saúde. São Paulo: Hucitec: Abrasco, 1993. p. 221-235.

VILLAROSA, Francesco Notarbartolo di. A estimativa rápida e a divisão do território no Distrito Sanitário. Brasília: Organização Pan-Americana de Saúde, 1993. 
